\title{
Ligand Exchange of Colloidal ZnO Nanocrystals from the High Temperature and Nonaqueous Approach
}

\author{
Jun Luo $^{1}$, Xingliang Dai ${ }^{1}$, Sai Bai ${ }^{1}$, Yizheng Jin ${ }^{1,2,3, *}$, Zhizhen $\mathrm{Ye}^{1,2}$, Xiaojun Guo ${ }^{4}$
}

(Received 17 July; accepted 30 August; published online 8 November 2013)

\begin{abstract}
Colloidal zinc oxide $(\mathrm{ZnO})$ nanocrystals generated from the high temperature and nonaqueous approache are attractive for use in solution-processed electrical and optoelectronic devices. However, the asprepared colloidal $\mathrm{ZnO}$ nanocrystals by this approach are generally capped by ligands with long alkyl-chains, which is disadvantage for solution-processed devices due to hindering charge transport. Here we demonstrate an effective ligand exchange process for the colloidal $\mathrm{ZnO}$ nanocrystals from the high temperature and nonaqueous approach by using n-butylamine. The ligand exchange process was carefully characterized. The thin films based on colloidal $\mathrm{ZnO}$ nanocrystals after ligand exchange exhibited dramatically enhanced UV photoconductivity. Keywords: ZnO; Nanoparticles; Ligand exchange; Thin films; Photoconductivity
\end{abstract}

Citation: Jun Luo, Xingliang Dai, Sai Bai, Yizheng Jin, Zhizhen Ye and Xiaojun Guo, "Ligand Exchange of Colloidal ZnO Nanocrystals from the High Temperature and Nonaqueous Approach", Nano-Micro Lett. 5(4), 274-280 (2013). http://dx.doi.org/10.5101/nml.v5i4.p274-280

\section{Introduction}

Colloidal nanocrystals are attractive for use in large area and low-cost electronic and optoelectronic devices due to the unique combination of solid state properties and possibility of employing high throughput printing and coating techniques $[1,2]$. $\mathrm{ZnO}$ is a direct wide bandgap semiconductor with many unique properties, such as high electron mobility, excellent optical transparency, low work function and environmentally friendly nature [3]. Colloidal $\mathrm{ZnO}$ nanocrystals have been utilized in several prototype solution-processed devices including field effect transistors, photodetectors, hybrid solar cells, memristive devices and organic solar cells (as electron transporting interlayers) [4-9]. These results reveal attractive potential applications of $\mathrm{ZnO}$ nanocrystals for solution-processed electronics. Note that in most literatures, the $\mathrm{ZnO}$ nanocrystals utilized in solution-processed devices were synthesized by hydrolysis of zinc salt in aqueous or alcoholic basic solutions.

Recently, a high temperature and nonaqueous approach, which was originated from the synthesis of CdSe quantum dots [10], was applied to the synthesis of $\mathrm{ZnO}$ nanocrystals. The higher reaction temperature, generally above $250^{\circ} \mathrm{C}$, led to improve crystalline features of $\mathrm{ZnO}$ nanocrystals [11]. This approach also allows effective size control in a wide range from about 3 $\mathrm{nm}$ up to $15 \mathrm{~nm}$ [11-13]. In addition, a few recent studies demonstrated the syntheses of doped $\mathrm{ZnO}$ nanocrystals by this approach, which generated materials with tailored electrical properties. For example, our group demonstrated the syntheses of alloyed $\mathrm{Mg}_{\mathrm{x}} \mathrm{Zn}_{1-\mathrm{x}} \mathrm{O}[12]$ and $\mathrm{Cd}_{\mathrm{x}} \mathrm{Zn}_{1-\mathrm{x}} \mathrm{O}$ [13] nanocrystals having tunable opti-

\footnotetext{
${ }^{1}$ State Key Laboratory of Silicon Materials, Department of Materials Science and Engineering, Zhejiang University, Hangzhou 310027, People's Republic of China

${ }^{2}$ Cyrus Tang Center for Sensor Materials and Applications, Zhejiang University, Hangzhou 310027, People's Republic of China

${ }^{3}$ Center for Chemistry of High-Performance and Novel Materials, Zhejiang University, Hangzhou 310027, People's Republic of China

${ }^{4}$ Department of Electronic Engineering, Shanghai Jiao Tong University, Shanghai 200240, People's Republic of China

*Corresponding author. E-mail: yizhengjin@zju.edu.cn
} 
cal bandgaps. Buonsanti et al. prepared $\mathrm{Al}^{3+}$ doped $\mathrm{ZnO}$ nanocrystals which had high free carrier concentrations [14]. These impressive progresses pave the way for potential applications on colloidal $\mathrm{ZnO}$ nanocrystals by high temperature and nonaqueous approach.

It was found that $\mathrm{ZnO}$ nanocrystals by the hightemperature approach were generally capped by ligands with long alkyl-chains, such as stearate ions $[11,12]$. These bulky ligands act as insulating barriers and block charge transport between neighboring particles. However, there is a lack of study on ligand exchange processes of $\mathrm{ZnO}$ nanocrystals in spite that they have been extensively investigated in the field of quantum dots $[1,15,16]$.

Herein we demonstrate ligand exchange of colloidal $\mathrm{ZnO}$ nanocrystals prepared by the high temperature and nonaqueous approach using n-butylamine. The ligand exchange process was carefully investigated. We also fabricated metal-semiconductor-metal (MSM) devices based on colloidal $\mathrm{ZnO}$ nanocrystals to examine the effects of ligand exchange on ultraviolet (UV) photoconductive properties.

\section{Experimental}

\section{Chemicals}

Zinc stearate and 1-octadecanol $(97 \%)$ were purchased from Alfa Aesar. 1-octadecene (ODE, tech 90\%) and n-butylamine (99.5\%) were purchased from Acros. All chemicals were used as received.

\section{Synthesis of $\mathrm{ZnO}$ nanocrystals}

Colloidal $\mathrm{ZnO}$ nanocrystals were synthesized according to reported literature methods $[11,12]$. Zinc stearate $(1 \mathrm{mmol})$ and $20 \mathrm{~g}$ of 1-octadecene (ODE) were loaded in a $100 \mathrm{~mL}$ three-necked flask and heated to $270^{\circ} \mathrm{C}$ under an argon flow. 1-Octadecanol (5 mmol) dissolved in $5 \mathrm{~g}$ of $\mathrm{ODE}$ at $200^{\circ} \mathrm{C}$ was quickly injected into the zinc stearate solution. The products were precipitated out by adding ethyl acetate and collected by centrifugation. Then the zinc oxide nanocrystals were washed twice with the combination of toluene/methanol. The resulting $\mathrm{ZnO}$ nanocrystals were dispersed in chloroform.

\section{Ligand exchange}

The purified $\mathrm{ZnO}$ nanocrystals were dissolved in $\mathrm{n}$ butylamine and stirred for $24 \mathrm{~h}$ at room temperature. Acetone was used to precipitate $\mathrm{ZnO}$ nanocrystals. The $\mathrm{ZnO}$ nanocrystals were collected by centrifugation and re-dispersed in chloroform. The effects of reaction time and temperature on the ligand exchange processes were investigated.

\section{Device fabrication}

The MSM devices were fabricated by spin-coating a solution of $\mathrm{ZnO}$ nanocrystals $(15 \mathrm{mg} / \mathrm{mL})$ onto a glass substrate, followed by annealing in air at $250^{\circ} \mathrm{C}$ for $1 \mathrm{~h}$. Aluminum was chosen as the electrodes because aluminum readily forms ohmic contacts with $\mathrm{ZnO}$ nanocrystals [17]. Aluminium layers $(100 \mathrm{~nm})$ were evaporated through a shadow mask to form "T" shape contacts. The spacing between the electrodes was 200 $\mu \mathrm{m}$. The length of the electrodes was $3 \mathrm{~mm}$.

\section{Characterization techniques}

The Ultraviolet-visible (UV-Vis) spectra of the $\mathrm{ZnO}$ nanocrystal solutions were recorded on a Shimadzu 3600 ultraviolet-visible-near infrared (UV-VisNIR) spectrophotometer. Fourier transform infrared (FTIR) spectra were collected by a Bruker Tensor 27 FTIR spectrophotometer. Transmission electron microscope (TEM) analyses of the $\mathrm{ZnO}$ nanocrystals were carried out by using a JEOL JEM 1230 microscope operated at $80 \mathrm{keV}$. X-ray diffraction (XRD) measurements were performed on an X'Pert PRO system operated at $40 \mathrm{keV}$ and $40 \mathrm{~mA}$ with $\mathrm{Cu} \mathrm{KR}$ radiation $(\lambda=1.5406 \AA)$. Thermo gravimetric analysis (TGA) of the $\mathrm{ZnO}$ nanocrystals was carried out on a SDT Q600 Simultaneous analyzer. Samples were heated from room temperature to $500^{\circ} \mathrm{C}$ at a rate of $10^{\circ} \mathrm{C} / \mathrm{min}$ under an air flow.

Electrical measurements of devices were carried out under vacuum with a base pressure of 2-3 $\mathrm{Pa}$ by using a semiconductor parameter analyzer (Agilent E5270B). UV excitation was provided by a UV light-emitting diode (365 nm, $280 \mathrm{~mW}$ ) and focused onto the devices with a spot size of ca. $2 \mathrm{~mm}$.

\section{Results and discussions}

\section{Surface ligand}

Figure 1(a) shows the FTIR spectra of the $\mathrm{ZnO}$ nanocrystals before and after ligand exchange. Before ligand exchange, the $\mathrm{ZnO}$ nanocrystals were capped with stearate ions as indicated by the characteristic asymmetric vibration at $1548 \mathrm{~cm}^{-1}$ and symmetric vibration at $1412 \mathrm{~cm}^{-1}$ of the $-\mathrm{COO}^{-}$groups $[11,18]$. After ligand exchange, the $-\mathrm{COO}^{-}$peaks were absent. Peaks at $2920 \mathrm{~cm}^{-1}, 2850 \mathrm{~cm}^{-1}$ and $1464 \mathrm{~cm}^{-1}$ respectively attributed to the asymmetrical and symmetrical stretching vibration and bending vibrations of $\mathrm{CH}_{2}$ groups were detected and significantly suppressed after ligand exchange. Figure 1(b) shows the TGA profiles of $\mathrm{ZnO}$ nanocrystals. Note that the slight mass loss below $150^{\circ} \mathrm{C}$ is attributed to the adsorption of water despite that the samples were dried overnight. The 
weight loss of $\mathrm{ZnO}$ nanocrystals before ligand exchange was greater than that after ligand exchange. The onset weight loss temperature of the sample before ligand exchange is $245^{\circ} \mathrm{C}$, higher than that after ligand exchange, $200^{\circ} \mathrm{C}$. Based on the above results, we conclude that the original ligands, stearate ions, of the colloidal $\mathrm{ZnO}$ nanocrystals have been effective replaced by

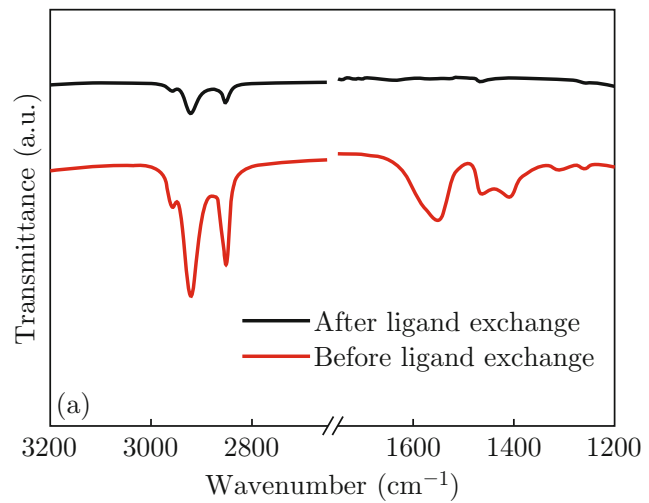

n-butylamine after ligand exchange.

\section{Morphology and structure}

TEM observations (Fig. 2(a)) show that the products prepared by the high temperature and nonaqueous approach before ligand exchange were nanopyramids.

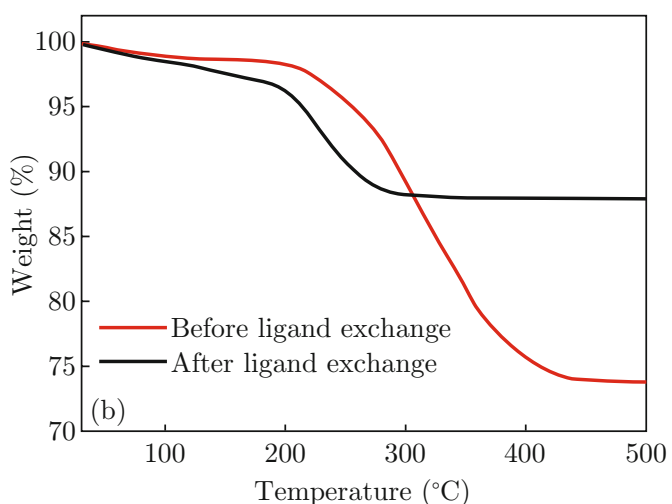

Fig. 1 (a) FTIR spectra and (b) TGA profiles of the $\mathrm{ZnO}$ nanocrystals before and after ligand exchange for $24 \mathrm{~h}$ at room temperature.
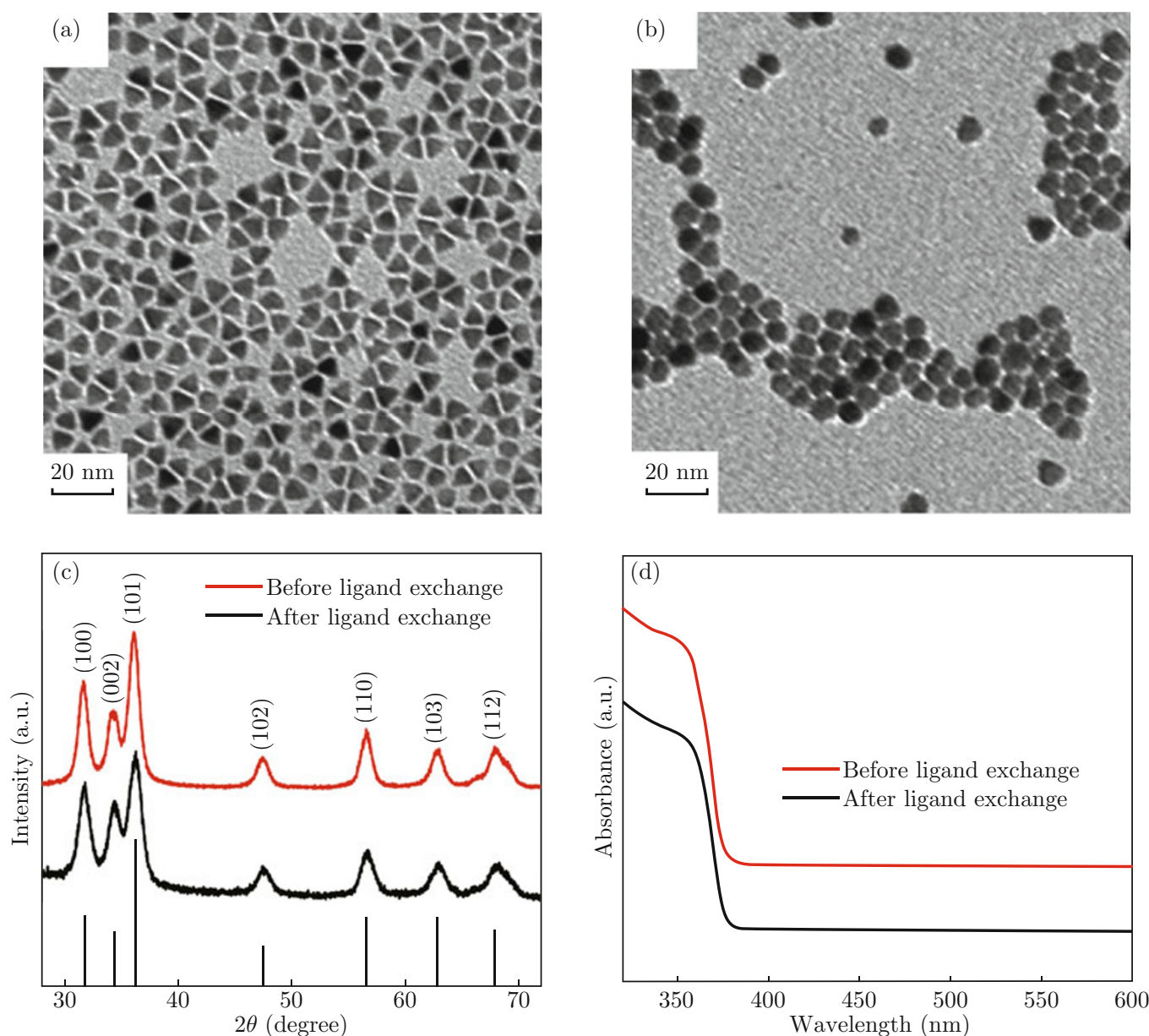

Fig. 2 TEM images of the $\mathrm{ZnO}$ nanocrystals before (a) and after (b) ligand exchange for $24 \mathrm{~h}$ at room temperature. (c) XRD patterns and (d) UV-Vis absorption spectra of the $\mathrm{ZnO}$ nanocrystals before and after ligand exchange for $24 \mathrm{~h}$ at room temperature. 
They converted to spherical particles (Fig. 2(b)) after ligand exchange. This morphological change may partially because the surface zinc ions, which bound to the original ligands of stearate ions, at the highly reactive sites, such as tips or corners of the nanopyramids, were stripped in the ligand exchange process. Etching of the surface atoms of colloidal nanocrystals capped by carboxylate ligands in protic amine solvent or shortchain alcohols has also been reported by other groups $[19,20]$. Figure 2(c) shows the XRD results of the $\mathrm{ZnO}$ nanocrystals before and after ligand exchange. Both profiles agree well with the wurtzite structure of $\mathrm{ZnO}$ (JCPDS: 36-1451). The average diameters determined by the Scherer's formula were $8.9 \mathrm{~nm}$ and $9.3 \mathrm{~nm}$ for that after and before ligand exchange, respectively. The UV-Vis spectra of the $\mathrm{ZnO}$ nanocrystal solutions before and after ligand exchange (Fig. 2(d)) exhibit almost identical absorption features in the UV region. The optical bandgaps for the $\mathrm{ZnO}$ nanocrystals determined by UV-Vis analyses are $3.36 \mathrm{eV}$. The absence of scattering components in the visible region of the spectra implies the excellent colloidal solubility of the $\mathrm{ZnO}$ nanocrystal solutions $[12,13]$.

\section{UV photoconductivity of MSM}

MSM devices based on as-prepared $\mathrm{ZnO}$ nanocrystals were fabricated. XRD result on the $\mathrm{ZnO}$ nanocrystals film annealed at $250^{\circ} \mathrm{C}$ for $1 \mathrm{~h}$ is shown in Fig. 3(a). The calculated average diameter is $9.2 \mathrm{~nm}$, which is almost the same as that of the $\mathrm{ZnO}$ nanocrystals before heat treatment. The current-voltage curves of the MSM devices with aluminum electrodes, which reveal the charge transport characteristics, are shown in Fig. 3(b) and $3(\mathrm{c})$. The results indicated that the devices based on $\mathrm{ZnO}$ nanocrystals before and after ligand exchange were both highly resistive in the dark. No UV photo response was observed for the devices based on $\mathrm{ZnO}$ nanocrystals capped by stearate ions. Regarding the devices based on $\mathrm{ZnO}$ nanocrystals after ligand exchange, the photocurrent increased by nearly seven orders of magnitude upon UV illumination. The low dark conductivity of the thin films based on $\mathrm{ZnO}$ nanocrystals after ligand exchange is due to the formation of depletion layer caused by the adsorption of oxygen molecules. Electron-hole pairs were generated in the thin films upon UV illumination, leading to the photo-desorption of the negatively charged adsorbed oxygen ions and the increase of the carrier concentrations [5,21]. The dramatically different UV photoconductive behavior of the thin films based on $\mathrm{ZnO}$ nanocrystals before and after ligand exchange suggests that the dominate factor that controls the photocurrent is the electrical coupling between neighboring particles. The large photocurrent of the devices based on $\mathrm{ZnO}$ nanocrystals after ligand exchange implies that trapping of free charges is a min- imum factor. This conjecture is supported by the high crystalline quality of $\mathrm{ZnO}$ nanocrystals from the high temperature and nonaqueous approach $[11,12]$.
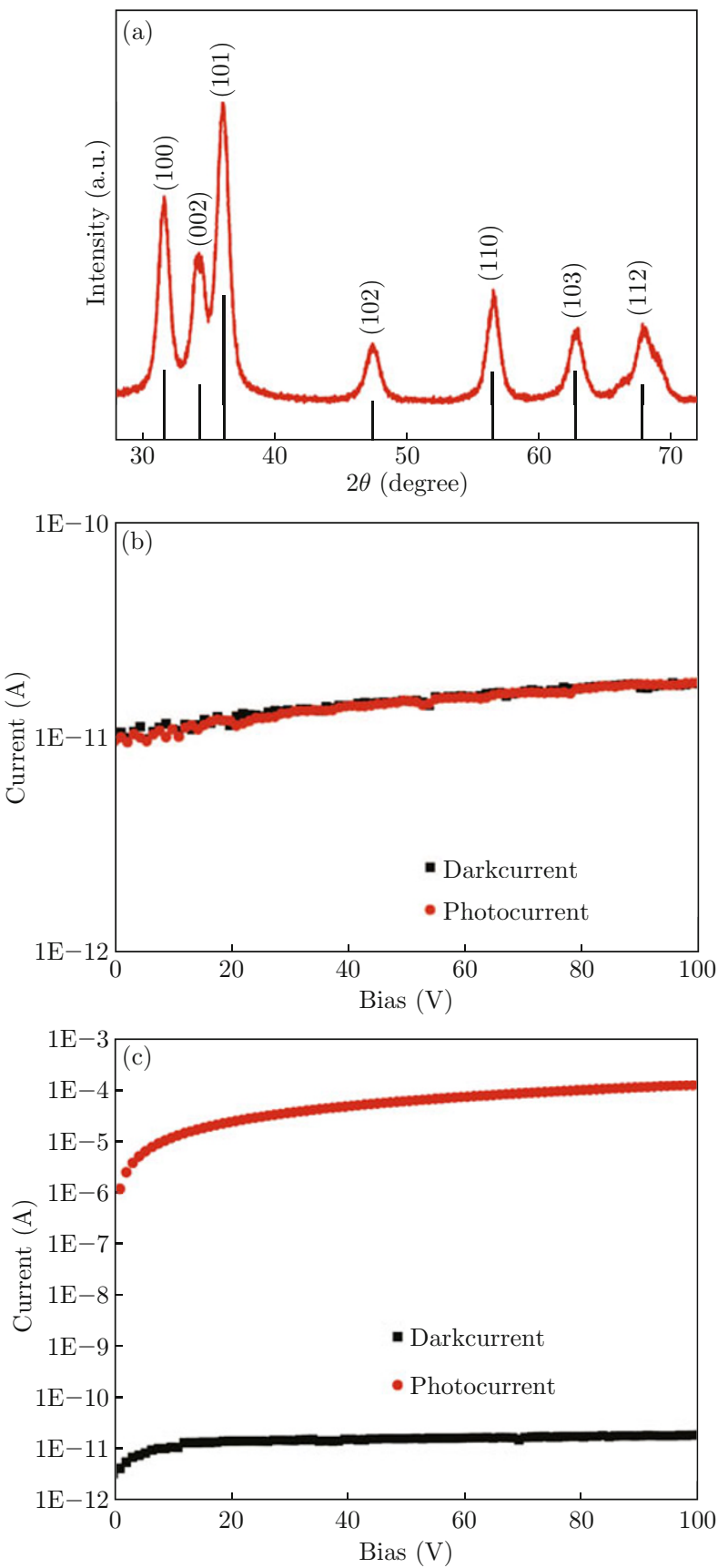

Fig. 3 (a) XRD pattern of $\mathrm{ZnO}$ nanocrystals that were annealed at $250^{\circ} \mathrm{C}$ for 1 hour. I-V characteristics of the MSM devices fabricated using $\mathrm{ZnO}$ nanocrystals before (b) and after (c) ligand exchange for $24 \mathrm{~h}$ at room temperature.

\section{Effects of reaction time and temperature}

The effects of reaction time and temperature on the ligand exchange processes were investigated by two sets of experiments. In the first set of experiments, the reaction time was set to be 12 and $48 \mathrm{~h}$ respectively,with 
other conditions for ligand exchange blank unchanged. As shown in Fig. 4(a), the ligand exchange was not completed in $12 \mathrm{~h}$, as evidenced by the residue vibration peaks of the $-\mathrm{COO}^{-}$groups. Figure $4(\mathrm{~b})$ shows the $\mathrm{UV}$-Vis spectra of the $\mathrm{ZnO}$ nanocrystal solutions after ligand exchange for $12 \mathrm{~h}$, and there was no change of absorption features. Figure 5(a) shows the TEM images of the $\mathrm{ZnO}$ nanocrystals which converted to spherical particles after ligand exchange for $12 \mathrm{~h}$ at room temperature. Photocurrent of devices from the $\mathrm{ZnO}$ nanocrystals which were ligand exchanged for 12 $\mathrm{h}$ upon identical UV illumination increased by only four orders of magnitude, much smaller than that of devices from the $\mathrm{ZnO}$ nanocrystals for $24 \mathrm{~h}$ because of in-complete ligand exchange (Fig. 6(a)). Extending the reaction time to $48 \mathrm{~h}$ did not cause distinguishable changes of either the FTIR spectrum (Fig. 4(a)), UVVis spectrum (Fig. 4(b)) and morphology (Fig. 5(b)) of the $\mathrm{ZnO}$ nanocrystals or the UV photoconductive behaviors (Fig. 6(b)) of the devices based on the ligand exchanged $\mathrm{ZnO}$ nanocrystals. In the second set of experiments, the reaction temperature was increased to $60^{\circ} \mathrm{C}$, which is about $20^{\circ} \mathrm{C}$ below the boiling temperature of n-butylamine with other conditions for ligand exchange unchanged. The resulting $\mathrm{ZnO}$ nanocrystals exhibited similar features comparing with the products after ligand exchange for $24 \mathrm{~h}$ at room temperature (Fig. 4(a), Fig. 4(b), Fig. 5(c) and Fig. 6(c)).

\section{Conclusion}

In summary, we demonstrated effective ligand exchange of colloidal $\mathrm{ZnO}$ nanocrystals from the high temperature and nonaqueous approach. The original ligands of long alkyl-chain stearate ions were replaced by n-butylamine. The ligand exchange process significantly improved electrical coupling between neighboring $\mathrm{ZnO}$ particles, leading to thin films exhibiting highly UV-sensitive photoconduction.

Our study may shed light on the future applications of colloidal $\mathrm{ZnO}$ nanocrystals from the high temperature and nonaqueous approach as functional materials for solution-processed devices.
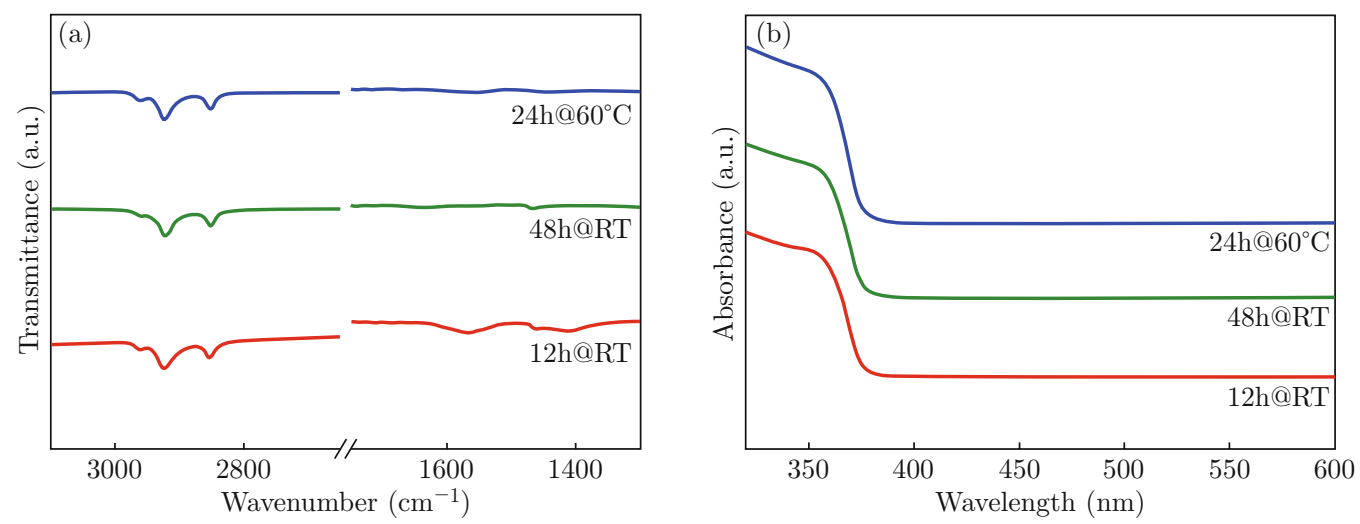

Fig. 4 (a) FTIR spectra and (b) UV-Vis absorption spectra of the $\mathrm{ZnO}$ nanocrystals after ligand exchange for $12 \mathrm{~h}, 48 \mathrm{~h}$ at room temperature (RT) and $24 \mathrm{~h}$ at $60^{\circ} \mathrm{C}$.
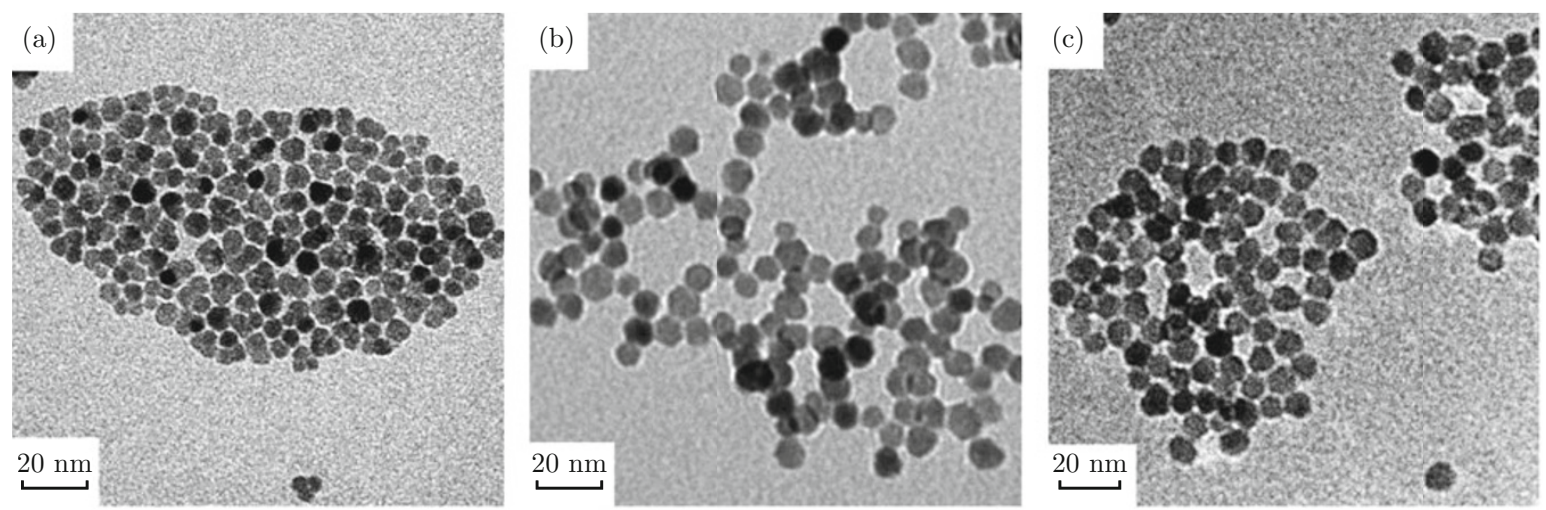

Fig. 5 TEM images of the $\mathrm{ZnO}$ nanocrystals after ligand exchange for $12 \mathrm{~h}$ (a), $48 \mathrm{~h}$ (b) at room temperature (RT) and 24 h (c) at $60^{\circ} \mathrm{C}$. 

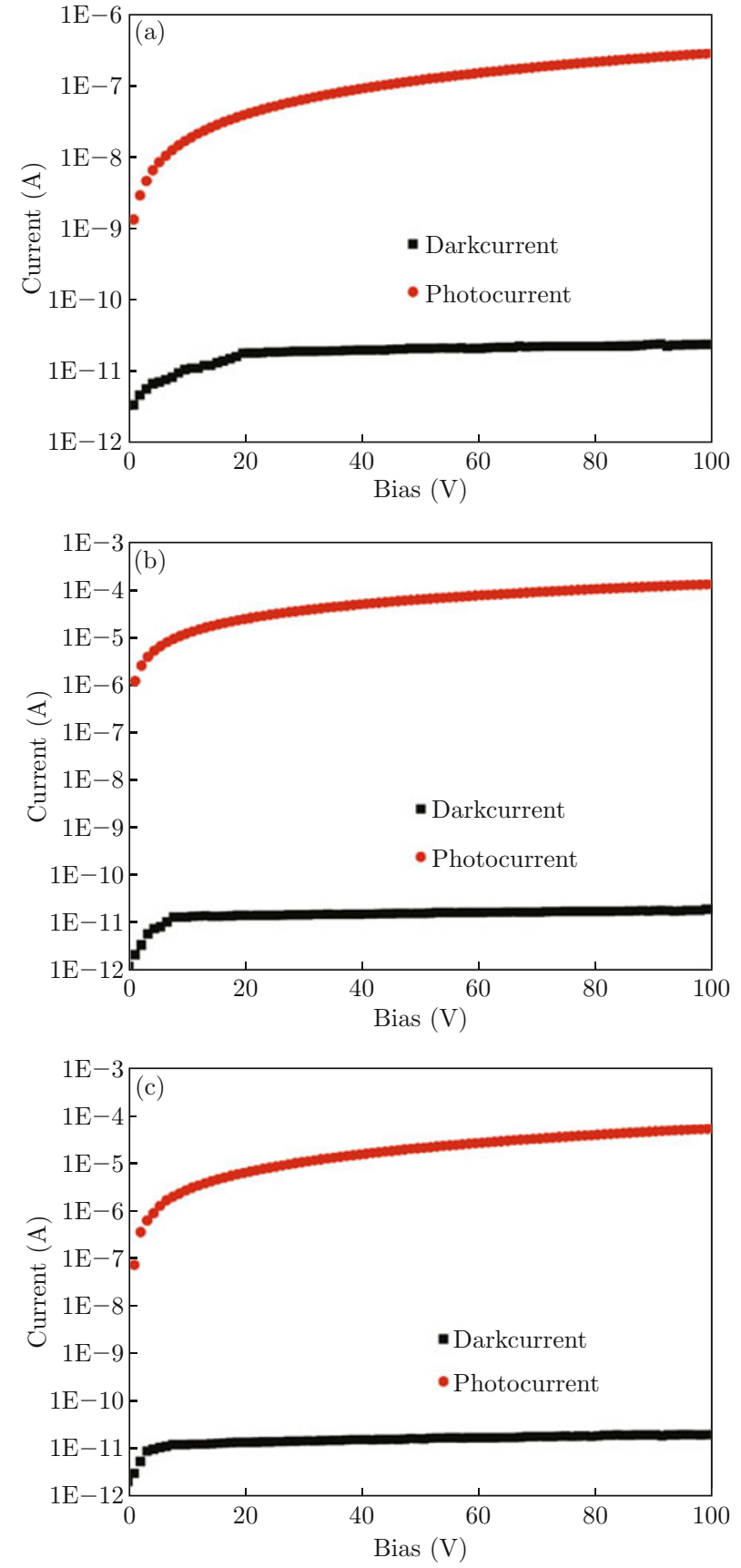

Fig. 6 I-V characteristics of the MSM devices fabricated using $\mathrm{ZnO}$ nanocrystals after ligand exchange for $12 \mathrm{~h}$ (a); $48 \mathrm{~h} \mathrm{(b)}$ at room temperature and $24 \mathrm{~h} \mathrm{(c)}$ at $60^{\circ} \mathrm{C}$.

\section{Acknowledgements}

This work is financially supported by the National Natural Science Foundation of China (51172203), the National High Technology Research and Development Program of China (2011AA050520), the Public Welfare Project of Zhejiang Province (2013C31057) and the Natural Science Funds for Distinguished Young Scholar of Zhejiang Province (R4110189).

\section{References}

[1] G. Konstantatos, I. Howard, A. Fischer, S. Hoogland, J. Clifford, E. Klem, L. Levina and E. H. Sargent, "Ultrasensitive solution-cast quantum dot photodetectors", Nature 442(7099), 180-183 (2006). http://dx. doi.org/10.1038/nature04855

[2] D. V. Talapin, J. S. Lee, M. V. Kovalenko, and E. V. Shevchenko, "Prospects of colloidal nanocrystals for electronic and optoelectronic applications", Chem. Rev. 110(1), 389-458 (2010). http://dx.doi.org/10. $1021 / \mathrm{cr} 900137 \mathrm{k}$

[3] Ü. Özgür, Ya. I. Alivov, C. Liu, A. Teke, M. A. Reshchikov, S. Doğan, V. Avrutin, S. J. Cho, and H. Morkoç, "A comprehensive review of $\mathrm{ZnO}$ materials and devices", J. Appl. Phys. 98(4), 041301-041403 (2005). http://dx.doi.org/10.1063/1.1992666

[4] B. Q. Sun and H. Sirringhaus, "Solution-processed zinc oxide field-effect transistors based on self-assembly of colloidal nanorods", Nano Lett. 5(12), 2408-2413 (2005). http://dx.doi.org/10.1021/n1051586w

[5] Y. Z. Jin, J. P. Wang, B. Q. Sun, J. C. Blakesley and N. C. Greenham, "Solution-processed ultraviolet photodetectors based on colloidal zno nanoparticles", Nano. Lett. 8(6), 1649-1653 (2008). http://dx.doi. org/10.1021/nl0803702

[6] W. J. E. Beek, M. M. Wienk and R. A. J. Janssen, "Efficient hybrid solar cells from zinc oxide nanoparticles and a conjugated polymer", Adv. Mater. 16(12), 1009-1013 (2004). http://dx.doi.org/ 10.1002/adma. 200306659

[7] H. M. P. Wong, P. Wang, A. Abrusci, M. Svensson, M. R. Andersson and N. C. Greenham, "Donor and acceptor behavior in a polyfluorene for photovoltaics", J. Phys. Chem. C 111(13), 5244-5249 (2007). http:// dx.doi.org/10.1021/jp068536f

[8] J. P. Wang, B. Q. Sun, F. Gao and N. C. Greenham, "Memristive devices based on solution-processed ZnO nanocrystals", Phys. Status Solidi A 207(2), 484-487 (2010). http://dx.doi.org/10.1002/pssa. 200925467

[9] J. B. You, C. C. Chen, L. T. Dou, S. Murase, H. S. Duan and S. A. Hawks, T. Xu, H. J. Son, L. P. Yu, G. Li and Y. Yang, "Metal oxide nanoparticles as an electron-transport layer in high-performance and stable inverted polymer solar cells", Adv. Mater. 24(38), 5267-5272 (2012). http://dx.doi.org/10. 1002/adma. 201201958

[10] C. B. Murray, D. J. Noms and M. G. Bawendi, "Synthesis and characterization of nearly monodisperse $\mathrm{CdE}(\mathrm{E}=$ sulfur, selenium, tellurium) semiconductor nanocrystallites", J. Am. Chem. Soc. 115(19), 8706-8715 (1993). http://dx.doi.org/10. 1021/ja00072a025

[11] Y. F. Chen, M. Kim, G. D. Lian, M. B. Johnson and X. G. Peng, "Side reactions in controlling the quality, yield, and stability of high quality colloidal nanocrystals", J. Am. Chem. Soc. 127(38), 13331-13337 (2005). http://dx.doi.org/10.1021/ja053151g 
[12] Y. F. Yang, Y. Z. Jin, H. P. He, Q. L. Wang, Y. Tu, H. M. Lu and Z. Z. Ye, "Dopant-induced shape evolution of colloidal nanocrystals: the case of zinc oxide", J. Am. Chem. Soc. 132(38), 13381-13394 (2010). http:// dx.doi.org/10.1021/ja103956p

[13] X. Wang, Y. Z. Jin, H. P. He, F. Yang, Y. F. Yang and Z. Z. Ye, "Bandgap engineering and shape control of colloidal $\mathrm{Cd}_{\mathrm{x}} \mathrm{Zn}_{1-\mathrm{x}} \mathrm{O}$ nanocrystals", Nanoscale 5(14), 6464-6468 (2013). http://dx.doi. org/10.1039/C3NR01124K

[14] R. Buonsanti, A. Llordes, S. Aloni, B. A. Helms and D. J. Milliron, "Tunable infrared absorption and visible transparency of colloidal aluminum-doped zinc oxide nanocrystals", Nano. Lett. 11(11), 4706-4710 (2011). http://dx.doi.org/10.1021/n1203030f

[15] H. T. Zhang, B. Hu, L. F. Sun, R. Hovden, F. W. Wise, D. A. Muller and R. D. Robinson, "Surfactant ligand removal and rational fabrication of inorganically connected quantum dots", Nano. Lett. 11(12), 5356-5361 (2011). http://dx.doi.org/10.1021/n1202892p

[16] A. Nag, M. V. Kovalenko, J. S. Lee, W. Y. Liu, B. Spokoyny and D. V. Talapin, "Metal-free inorganic ligands for colloidal nanocrystals: $\mathrm{S}^{2-}, \mathrm{H}^{S-}, \mathrm{Se}^{2-}$, $\mathrm{HSe}^{-}, \mathrm{Te}^{2-}, \mathrm{HTe}^{-}, \mathrm{TeS}_{3}^{2-}, \mathrm{OH}^{-}$, and $\mathrm{NH}^{2-}$ as surface ligands", J. Am. Chem. Soc. 133(27), 10612-10620 (2011). http://dx.doi.org/10.1021/ja2029415

[17] H. K. Kim, K. K. Kim, S. J. Park, T. Y. Seong and I. Adesida, "Formation of low resistance nonalloyed
$\mathrm{Al} / \mathrm{Pt}$ ohmic contacts on n-type $\mathrm{ZnO}$ epitaxial layer", J. Appl. Phys. 94(6), 4225-4227 (2003). http://dx. doi.org/10.1063/1.1604475

[18] Q. Y. Qu, H. W. Geng, R. X. Peng, Q. Cui, X. H. $\mathrm{Gu}$, F. Q. Li and M. T. Wang, "Chemically binding carboxylic acids onto $\mathrm{TiO}_{2}$ nanoparticles with adjustable coverage by solvothermal strategy", Langmuir 26(12), 9539-9546 (2010). http://dx.doi.org/ 10.1021/la100121n

[19] A. Hassinen, I. Moreels, K. D. Nolf, P. F. Smet, C. Martins and Z. Hens, "Short-chain alcohols strip Xtype ligands and quench the luminescence of PbSe and CdSe quantum dots, acetonitrile does not", J. Am. Chem. Soc. 134(51), 20705-20712 (2012). http://dx. doi.org/10.1021/ja308861d

[20] O. Chen, Y. A. Yang, T. Wang, H. M. Wu, C. G. Niu, J. H. Yang and Y. C. Cao, "Surfacefunctionalization-dependent optical properties of IIVI semiconductor nanocrystals", J. Am. Chem. Soc. 133(43), 17504-17512 (2011). http://dx.doi.org/10. $1021 / \mathrm{ja208337r}$

[21] C. Soci, A. Zhang, B. Xiang, S. A. Dayeh, D. P. R. Aplin, J. Park, X. Y. Bao, Y. H. Lo and D. Wag, "Zno nanowire UV photodetectors with high internal gain", Nano. Lett. 7(4), 1003-1009 (2007). http://dx.doi. org/10.1021/nl070111x 